\title{
Duration of untreated psychosis/illness and brain volume changes in early psychosis
}

Charlotte Rapp ${ }^{a}$, Carlos Canela ${ }^{a}$, Erich Studerus, Anna Walter, Jacqueline Aston,

Stefan Borgwardt, Anita Riecher-Rössler*

University of Basel Psychiatric Hospital, Center for Gender Research and Early Detection, Kornhausgasse 7, $\mathrm{CH}-4051$ Basel, Switzerland

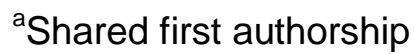

*Corresponding author:

Prof. A. Riecher-Rössler

University of Basel Psychiatric Hospital

Center for Gender Research and Early Detection

Kornhausgasse 7

$\mathrm{CH}-4051$ Basel, Switzerland

Tel.: +4161325 8161

Fax: +41613258160

E-mail: Anita.Riecher@upkbs.ch

Word count main text: 3718 (max)

Word count abstract: 242 (max) 


\section{Abstract}

The time period during which patients manifest psychotic or unspecific symptoms prior to treatment (duration of untreated psychosis, DUP, and the duration of untreated illness, DUI) has been found to be moderately associated with poor clinical and social outcome. Equivocal evidence exists of an association between DUP/DUI and structural brain abnormalities, such as reduced hippocampus volume (HV), pituitary volume (PV) and grey matter volume (GMV). Thus, the goal of the present work was to examine if DUP and DUI are associated with abnormalities in HV, PV and GMV. Using a region of interest (ROI) based approach, we present data of 39 patients from the Basel FePsy (Früherkennung von Psychosen, early detection of psychosis) study for which information about DUP, DUI and HV, PV and GMV data could be obtained. Twenty-three of them were first episode psychosis (FEP) and 16 at-risk mental state (ARMS) patients who later made the transition to frank psychosis. In unadjusted analyses, we found a significant positive correlation between DUP and PV in FEP patients. However, when adjusted for covariates, we found no significant correlation between DUP or DUI and HV, PV or GMV anymore. There only was a trend for decreasing GMV with increasing DUI in FEP. Our results do not comprehensively support the hypothesis of a "toxic" effect of the pathogenic mechanism underlying untreated psychosis on brain structure. If there is any effect, it might rather occur very early in the disease process, during which patients experience only unspecific symptoms.

Keywords: first episode psychosis, at-risk mental state; grey matter volume, hippocampal volume; pituitary volume 


\section{Introduction}

Patients with psychosis often experience unspecific and psychotic symptoms for long periods before appropriate antipsychotic treatment is initiated (Fusar-Poli et al., 2013). The time period between first self-perceived signs of a change in well-being or unspecific symptoms and treatment is called "duration of untreated illness" (DUI); the time period between the development of the first psychotic symptoms and treatment is called "duration of untreated psychosis" (DUP) (Norman and Malla, 2001). Longer DUP and DUI have been consistently found to be associated with poor clinical and social outcomes, hence the need for early intervention services which create better outcomes in the critical period of the first 2-5 years of the disease (Bangalore et al., 2009; Crumlish et al., 2009; Harris et al., 2005; Keshavan et al., 2003; Marshall et al., 2005; Norman and Malla, 2001; Perkins et al., 2005). It has been hypothesized, that this might be due to a "toxic" effect of ongoing, untreated psychosis, respectively the effect of the untreated pathogenic mechanism underlying psychotic symptoms (Wyatt and Henter, 2001). The investigation if brain volume is affected in the early phases of psychosis has therefore become an important focus of research.

To better understand this possible process, several research groups have investigated the relationship between DUP and different brain structures (Büschlen et al., 2011; Crespo-Facorro et al., 2007a; Crespo-Facorro et al., 2007b; Ho et al., 2005; Ho et al., 2003; Hoff et al., 2000; Lappin et al., 2006; Takahashi et al., 2007). The results of these studies were summarized in two systematic reviews (Anderson et al., 2015; Rund, 2014), both finding minimal evidence for the "neurotoxicity" hypothesis. Rund et al. (2014) suggested in his review that there might be a threshold value for a toxic effect of psychosis rather than a linear relationship 
between DUP and a neurotoxic effect and that several of the evaluated studies might not have had a long enough DUP to detect a toxic effect of active psychosis (Rund, 2014).

One of the key regions to be investigated is the hippocampus, which is involved in memory functions and complex behaviors, including stress responses (Small et al., 2011), and has been proposed to be important in the development of schizophrenia (Antonova et al., 2004; Heckers and Konradi, 2002; Koolschijn et al., 2010; Phillips et al., 2002). It is among the most consistently reported abnormal brain regions in schizophrenia (Adriano et al., 2012) and highly interconnected with other regions of the brain. There is some evidence suggesting a change of the hippocampal volume (HV) during the early stages of a psychotic disorder. HV has been found to be decreased in patients with first episode psychosis (FEP) and patients with an at-risk mental state (ARMS) for psychosis (e.g. Buehlmann et al., 2010; Dean et al., 2016; Wood et al., 2010) compared to healthy controls (HC) (Adriano et al., 2012) .

Although it might be inferred from these findings that there is a time period at the beginning of the disease in which HV changes, it is yet unknown whether and when such changes actually occur. According to the "neurotoxicity" hypothesis, HV changes would be expected to increase the longer untreated symptoms persist. Nonetheless, to our knowledge no clear association between DUP and HV has been found up to now (Ho et al., 2005).

Another region that has been investigated recently and which seems to be affected in the early stages of the disease is the pituitary volume (PV) (Büschlen et al., 2011). A recent meta-analysis of studies investigating the volumes of the pituitary in patients with schizophrenia, FEP, schizotypical disorder or ARMS and healthy controls found 
a trend for larger PVs in both ARMS patients with later transition to psychosis and FEP patients compared to HC (Nordholm et al., 2013). Whether there is an association between the duration of untreated symptoms and volume changes in the pituitary is still unclear due to inconsistent results.

Several studies have also found volumetric changes of various grey matter regions in early stages of psychosis and ARMS (Borgwardt et al., 2007; Borgwardt et al., 2008; Chua et al., 2007; de Castro-Manglano et al., 2011; Witthaus et al., 2009). Investigations on the correlation between DUP and grey matter volume (GMV) changes have yielded equivocal results (Ho et al., 2003; Hoff et al., 2000; Lappin et al., 2006; Malla et al., 2011; Penttila et al., 2010; Takahashi et al., 2007).

Studies investigating a possible correlation of DUI and GMV abnormalities found similar equivocal results. Bangalore et al. found a significant inverse correlation between DUI and the volume of some grey matter regions (Bangalore et al., 2009), Velakoulis et al. found right medial temporal, medial cerebellar and bilateral anterior cingulate GMV changes, and white matter volume loss in the right posterior limb of the internal capsule associated with a longer DUI (Velakoulis et al., 2002), whereas Hoff et al. (2000) could not find an significant correlation between changes in GMV and DUI. In line with the hypothesis of a "neurotoxicity" of untreated psychosis, it might be surmised that the longer untreated psychotic processes/symptoms persist, the more pronounced structural alterations of HV, PV and GMV could be.

The objective of the present study was to investigate a possible correlation between DUP/DUI and different structural brain abnormalities (HV, PV and GMV) that have been found to be affected in early stages of psychosis. On the basis of previous longitudinal studies of DUP and other volume abnormalities in early stages of 
psychosis, we tested the hypothesis that a longer DUP or DUI would be associated with a decrease in HV, PV and GMV. This is the first study to look at the relationship between all three brain parts, HV, PV and GMV, and DUP/DUI in the same study. Additionally, in contrast to most other studies, this study mainly includes antipsychotic-free subjects, which is highly relevant due to the fact that antipsychotic treatment itself can lead to brain structural changes (Vita et al., 2015).

\section{Methods}

\subsection{Participants}

This study was part of the FePsy (Früherkennung von Psychosen; early detection of psychosis) study (Riecher-Rössler et al., 2007), a multi-domain study on the early detection of psychosis. Subjects with an ARMS or FEP were recruited from a service area covering about 200,000 inhabitants in and around Basel, Switzerland, into the study via the FePsy Clinic at the University Hospital Basel, which was set up specifically to identify, assess and treat individuals in the early stages of psychosis. The study design and criteria for identification of ARMS and FEP subjects have been described in detail previously (Riecher-Rössler et al., 2007).

The study sample overlaps with previous samples reported on from the FePsy study (Borgwardt et al., 2006; Buehlmann et al., 2010; Büschlen et al., 2011; RiecherRössler et al., 2007; Walter et al., 2012b; Walter et al., 2014). The study was approved by the Ethics Committee of Basel, Switzerland (EKBB) and written informed consent was obtained from the participants.

In this study, we present data of 39 patients from the Basel FePsy study for which information about DUP, DUI and region of interest (ROI) data could be obtained. 
Twenty-three patients were identified as FEP patients and 16 as ARMS individuals who later made the transition to frank psychosis (ARMS-T). The service is fully responsible for all ARMS and FEP patients of a catchment area (Kanton BaselStadt). Our study sample did not significantly differ from all patients of our service in the respective period regarding sociodemographic characteristics.

\section{Screening procedure}

For screening purposes and measuring the severity of (pre-)psychotic phenomena, we used the Basel Screening Instrument for Psychosis (BSIP) (Riecher-Rössler et al., 2008). Individuals were assessed and classified as individuals with an ARMS, FEP or "not at risk for psychosis" (other psychiatric diseases). All assessments were conducted by experienced psychiatrists/psychologists who underwent regular training.

\section{Inclusion criteria}

We included FEP patients and ARMS individuals who later made the transition to frank psychosis (ARMS-T) according to the PACE (Personal Assessment and Crisis Evaluation) criteria proposed by Yung et al. (1998) (Yung et al., 1998) which have also been employed in previous MRI studies of patients with an ARMS (Borgwardt et al., 2006; Garner et al., 2005; Pantelis et al., 2003; Velakoulis et al., 2006).

\section{Exclusion criteria}

Patients aged below 18 years with insufficient knowledge of German, IQ below 70, a previous episode of schizophrenic psychosis (treated with antipsychotics for more than 3 weeks), a psychosis due to organic reasons or substance dependency and 
psychotic symptoms within a clearly diagnosed affective psychosis or borderline personality disorder were excluded from the study.

\subsection{Acquisition and analysis of MRI data}

All participants received MRI within an average 25 days after entering into our early detection service.

Since this study is a part of the FePsy project, the acquisition of the presented MRI data has already been described elsewhere (Buehlmann et al., 2010; Büschlen et al., 2011).

Briefly, a SIEMENS (Erlangen, Germany) MAGNETOM VISION 1.5 T scanner was used at the University Hospital Basel to scan all subjects at the inclusion to the study, i.e. when they first presented with prodromal or psychotic symptoms. Foam padding and velcro straps were used to minimize head movement. A three-dimensional volumetric spoiled gradient recalled echo sequence generated 176 contiguous, $1 \mathrm{~mm}$ thick sagittal slices. Imaging parameters were: time-to-echo, 4 ms; time-to-repetition, $9.7 \mathrm{~ms}$; flip angle, 12 ; matrix size, $200 \times 256$; field of view, $25.6 \times 25.6 \mathrm{~cm}$ matrix; voxel dimensions, $1.28 \times 1 \times 1 \mathrm{~mm}$.

A detailed description of the measuring processes of the regions of interest (ROI) and GMV used in this sample has been published elsewhere (Harris et al., 2005; Phillips et al., 2002). In summary, a ROI approach was used to measure HV and PV manually by a single tracer with a mouse-driven cursor, using the interactive public domain software program AMIRA which displays all three planes simultaneously (Kappos et al., 2006). All measurements of HV and PV were carried out by a trained and blinded rater (AW). The intra-rater intra-class correlation coefficient and inter- 
rater reliability have been reported in our previously published studies (Walter et al., 2012a; Walter et al., 2014). To assess GMV, a voxel-based morphometry, using the fully automated software SIENAX (www.fmrib.ox.ac.uk/fsl), allowed us to estimate the whole brain volumes from a single image, normalized for skull size (Smith et al., 2007) . After stripping non-brain tissue, the software estimates the scaling between the subject's image and standard space using the brain and skull images. It then runs tissue segmentation to estimate the volume of brain tissue and multiplies this by the estimated scaling factor to reduce head-size-related variability between subjects (Smith et al., 2002).

\subsection{DUP and DUI}

DUI was defined as the time period between first self-perceived signs of a change in well-being and first contact with our specialized early detection service. DUP was defined as the time period between the appearance of the first positive psychotic symptom and first contact with our specialized early detection service. DUP was only assessed in FEP patients because it was almost zero in our ARMS-T patients due to our close follow-up during the at-risk mental state and prompt treatment at transition.

DUI was determined by using the Basel Interview for Psychosis (BIP) (RiecherRössler et al., 2015; Riecher-Rössler et al., 2007), a structured and specifically developed interview for the early detection of psychosis, allowing an exact description of the onset of all symptoms. The DUP was assessed using the Basel Screening Interview for Psychosis (BSIP) (Riecher-Rössler et al., 2008).

Both DUP and DUI were assessed according to the patient's subjective response but also by using other available information resources (e.g. information from family members, medical histories). 


\section{Psychopathology measures}

Positive symptoms were assessed with the 4 items: hallucinations, suspiciousness, unusual thought content, and conceptual disorganization of the Brief Psychiatric Rating Scale (BPRS) (Ventura et al., 1993). Negative symptoms were assessed with the Scale for the Assessment of Negative Symptoms (SANS) (Andreasen, 1983).

\subsection{Statistical analysis of clinical and demographic data}

Statistical analyses were performed using the R environment for statistical computing (R Development Core Team, 2012). Due to a strong positive skew, both DUP and

DUI were anchored at 1 and then log transformed. Two tailed $t$-tests for the continuous and Fisher's Exact or $\chi^{2}$ tests for the categorical variables were used in order to compare groups for demographic and clinical data $(p<0.05)$.

Associations of brain structural volumes with DUP and DUI were analyzed using linear regression and mixed effects (LME) models, in which log transformed DUP or DUI served as outcome variables and brain structural volumes as predictors. Linear regression models were used for PV and whole brain GMV and LME models for HV. LME models were used in the latter case to account for repeated measures resulting from assessing HV at both the left and right hemispheres. The within subject factor hemisphere and the interaction between hemisphere and DUI/DUP was therefore included in all LME models. The random effect structure of the LME models consisted of a random intercept per subject.

All models included age and gender as covariates. Models with PV and HV as outcome variables additionally included whole brain volume as covariate. Furthermore, models with DUI included group (ARMS-T vs. FEP) and group x DUI 
interaction terms and in case of HV group $\mathrm{x}$ hemisphere and group $\mathrm{x}$ hemisphere $\mathrm{x}$ DUI interaction terms. All continuous variables were z-transformed before entering the models to get fully standardized regression coefficients for continuous variables and y-standardized regression coefficients for binary variables.

\section{Results}

In this paper we present data of 39 individuals (23 FEP, 16 ARMS-T) screened between 01.03.2000 and 29.2.2004, in whom the MRI scans were completed. The sociodemographic, clinical characteristics and diagnoses of the sample are presented in Table 1. As was to be expected, the BPRS score was higher in FEP than in ARMS-T patients $(p=0.024)$, while the SANS score did not differ significantly between the two groups $(p=0.648)$.

The median DUP (only assessed in FEP) was 3.7 months (mean: 11.3; SD: 16.6). The median DUI for the total sample was 36 months (mean: 52.5; SD: 59.1), 51 months (mean: 47.9; SD: 37.7) for ARMS-T and 27 months (mean: 55.8; SD: 71.6) for FEP.

ARMS-T patients had significantly bigger left HV than FEP patients $(p=0.020)$. There were no significant differences between the ARMS-T and FEP groups in the right $\mathrm{HV}, \mathrm{PV}$, and GMV.

Table 2 displays regression coefficients and $p$-values of the models testing associations between DUP and brain structural volumes in FEP patients. DUP was not significantly associated with HV, PV and GMV in FEP patients when adjusted for confounders (age, sex, whole brain volume). However, when the model was only 
adjusted for whole brain volume, there was a positive relationship between DUP and $\mathrm{PV}(p=0.042)$

Four (25\%) of the ARMS-T patients and $9(39 \%)$ of the FEP patients were taking antipsychotics at the time of MRI assessment. Additionally, one ARMS-T patient had been taking antipsychotics before but not during the MRI assessment. All other patients were antipsychotic-naïve. Since according to our inclusion criteria patients were only allowed to have taken antipsychotics for up to three weeks at the time of inclusion, all patients were treated for a relatively short period of time. Moreover, patients were exclusively treated with low to moderate doses of either olanzapine or risperidone.

Table 3 displays the results of the models testing associations between DUI and brain structural volumes in FEP and ARMS-T patients combined. DUI was not significantly associated with PV and HV and - as indicated by non-significant interaction terms - the effect of DUI was not moderated by group (FEP vs. ARMS-T) or hemisphere (left vs. right) in these volumes. For whole brain volume, there was a significant interaction between group and DUI $(p=0.027)$, indicating different associations between DUI and whole brain volumes in ARMS-T and FEP patients. We therefore performed separate regression models for ARMS-T and FEP patients and found that there was a trend for decreased gray matter volume with increasing DUI in FEP $(p=0.093)$ but not in ARMS-T patients. When the model was calculated without adjusting for confounders, the results did not change significantly. 


\section{Discussion}

Using an ROI-based approach we investigated associations between PV, HV, GMV and DUP/DUI. To our knowledge, our study is one of the first to investigate the effect of DUI/DUP on HV, PV and GMV in the same patients. Our study did not find associations between DUP/DUI and brain volume which confirms findings of many earlier studies.

In accordance with other studies (Ho et al., 2005; Takahashi et al., 2007) we found that HV was neither significantly associated with DUP nor with DUI. Penttilä et al. (Penttila et al., 2010) found a correlation between DUP and the right HV that we could not replicate. One possible explanation for this discrepancy is that in their study the MRI was taken many years after the ending of DUP (mean duration between onset of treatment and MRI scan of more than 10 years), whereas in our study the MRI was conducted at baseline (i.e. immediately before treatment initiation). Thus, it is possible that a longer DUP might affect the right HV only at a later stage of the illness.

In the unadjusted analysis, there was a significant positive correlation between DUP and PV. However, we found no association between DUP/DUI and PV when adjusted for covariates. An increased PV has been found in the prodromal phase (Garner et al., 2005; Pariante et al., 2005; Pariante et al., 2004) and the early stages of psychotic disease (Büschlen et al., 2011; Walter et al., 2014). From our results it is not clear whether the duration of untreated psychosis plays a role for this increase.

Consistent with other studies (Ho et al., 2003; Lappin et al., 2006; Penttila et al., 2010) we found no correlation between GMV and DUP. The correlation between 
DUP and GMV Malla et al. (Malla et al., 2011) found might have been due to the inclusion of patients with affective psychosis. An analysis of only those individuals with schizophrenia found no correlation with DUP in that study either.

Although our results could not reveal a statistically significant correlation between DUI and GMV in both groups, we found a statistical trend for a negative correlation between DUI and GMV in the FEP group. This could suggest a possible negative association of untreated, very early, non-specific psychiatric symptoms with GMV in FEP, which is somewhat in accordance with a meta-analysis investigating the relationship between DUI and different GMV areas (Anderson et al., 2015). However, from our results, no causal conclusions can be drawn.

HV, PV and GMV have been found to be altered in the early stages of the illness (Büschlen et al., 2011; Koolschijn et al., 2010; Pantelis et al., 2003), thus raising the question whether there might be a damaging impact of the prodromal phase or early untreated psychosis on said structures. In the last decade, most studies have investigated the time period when psychotic symptoms are already apparent (DUP) and yielded equivocal results. Generally, such studies were conducted with small samples and therefore were underpowered to reliably detect small effects. Thus, the replication of known results becomes an important aim in this field of research. Only few research groups have expanded their focus and included the prodromal stage (DUI), such as we did in our study.

Different mechanisms causing the neurotoxic effect of psychosis have been suggested: e.g. glutamatergic excitotoxicity (de la Fuente-Sandoval et al., 2011), 
elevated dopamine levels (Keshavan et al., 1998) or persistent catecholaminergic activity (Bangalore et al., 2009).

Another possible reason for volume changes in the first stages of psychosis might be hormonal abnormalities, which have consistently been reported (Riecher-Rössler et al., 2013; Walker et al., 2008). Increased levels of cortisol have been found in some patients with increased risk for psychosis (Walker et al., 2013); such higher levels seem to be associated with reduced HV (Mondelli et al., 2010).

Higher prolactin levels have also been found in antipsychotic-naïve patients with schizophrenia (Garcia-Rizo et al., 2012), FEP (Riecher-Rössler et al., 2013) and ARMS (Aston et al., 2010; Ittig et al., 2016). Since a higher prolactin production is known to be associated with an enlargement of the PV (MacMaster et al., 2007), a higher prolactin secretion might explain why increased PV have been found during the prodromal phase (Riecher-Rössler et al., 2013).

It has been hypothesized that the psychological distress during prodromal states and emerging psychosis might lead to hyperprolactinemia (Riecher-Rössler et al., 2013) and hypercortisolism, which in turn might cause structural changes in PV and HV. In line with the hypothesis of a "neurotoxicity" of untreated psychosis, it might be surmised that the longer such processes/symptoms and psychological distress persist, the more pronounced structural alterations of HV and PV could be.

Investigations focusing on DUP/DUI and reduced cognitive functioning as another possible "toxic" effect have yielded similarly equivocal results regarding the "neurotoxicity" hypothesis (Rapp et al., 2013). Other factors (i.e. social decline, 
substance abuse, etc.) might be responsible for the worse outcome associated with longer DUI/DUP (Broussard et al., 2013).

Besides a "general" neurotoxicity hypothesis, it seems important to maintain that this "toxic" process might also only occur in a subgroup of psychosis patients.

Furthermore, first episode psychosis might be in a too early phase of the disease to detect this phenomenon.

In general, the comparability across studies may be reduced due to different anatomic ROI definitions, biases in voxel-based morphometry (Fusar-Poli et al., 2013), and different MRI acquisition parameters (e.g. different slice thickness). Another methodological problem are the different definitions and measurements of DUP and DUI in different studies (Polari et al., 2011), which make comparisons difficult, as does the inclusion of different patient groups (e.g. affective psychosis, etc.) since some brain volume anomalies might be connected to other symptoms (i.e. depressive symptoms) (Koolschijn et al., 2010). It has also been suggested that defining DUP just as a period of time might not be enough when investigating a possible toxicity of a pathogenic mechanism underlying psychosis, since this definition of DUP makes no difference between individuals who experience continuous symptoms during DUP and others who suffer symptoms for short periods with long intervals before treatment. It is also possible that some individuals with a faster progression of the disease suffer greater structural brain changes but are hospitalized or treated sooner, resulting in a shorter DUP. Additionally, patients that have a reduced GMV might suffer from cognitive deficits that hinders them to get access to fast treatment. 


\subsection{Limitations}

As this study has a cross-sectional design, no causal relationships but only correlational relationships can be established. On the other hand longitudinal studies on this topic seem hardly feasible, as individuals usually do not seek help immediately when first symptoms occur. Also, our sample only comprises 39 patients, so that small effects cannot be detected. This study examined whole grey matter volume and hippocampus but did not examine other important cortical areas (frontal regions, superior temporal gyrus, etc). Other potentially influencing factors on brain volumes apart from the disease could not be controlled for. Since the number of tested brain volumes were relatively small and since we had limited power, we did not want to further reduce power by performing correction for multiple testing.

\subsection{Conclusions}

We found a significant positive correlation between DUP and PV in FEP patients. However, when adjusted for covariates, we found no significant correlation between DUP or DUI and HV, PV or GMV anymore. There only was a trend for decreasing GMV with increasing DUI in FEP. Our results do therefore not comprehensively support the hypothesis of a "toxic" effect of the pathogenic mechanism underlying untreated psychosis on brain structure. If there is any effect, it might rather occur very early in the disease process, during which patients experience only unspecific symptoms (during DUI).

Conflict of interest: none of the authors have any conflicts of interests to declare. 
Table 1: Demographic and clinical sample characteristics

\begin{tabular}{|c|c|c|c|c|}
\hline & $\begin{array}{l}\text { Combined } \\
\qquad \mathrm{N}=39\end{array}$ & $\begin{array}{c}\text { ARMS-T } \\
\mathrm{N}=16\end{array}$ & $\begin{array}{l}\text { FEP } \\
\mathrm{N}=23\end{array}$ & $p$-value \\
\hline Gender: & & & & 0.734 \\
\hline Women & $11(28.2 \%)$ & $5(31.2 \%)$ & $6(26.1 \%)$ & \\
\hline Men & $28(71.8 \%)$ & $11(68.8 \%)$ & $17(73.9 \%)$ & \\
\hline Age & $27.1(6.4)$ & $26.8(6.6)$ & $27.2(6.5)$ & 0.848 \\
\hline Years of education & $10.3(2.8)$ & $10.7(2.2)$ & $10.0(3.2)$ & 0.464 \\
\hline BPRS total score & $46.8(11.9)$ & $41.8(9.4)$ & $50.5(12.4)$ & 0.024 \\
\hline SANS total score & $32.0(18.8)$ & $30.3(18.4)$ & $33.1(19.5)$ & 0.648 \\
\hline \multicolumn{5}{|l|}{ Diagnoses $^{1}$} \\
\hline Paranoid Schizophrenia & & $2(12.5 \%)$ & $15(65.2 \%)$ & \\
\hline Undifferentiated Schizophrenia & & $2(12.5 \%)$ & $1(4.3 \%)$ & \\
\hline Acute transient psychotic disorder & & $212.5 \%)$ & $4(17.4 \%)$ & \\
\hline Schizoaffective disorder & & $212.5 \%)$ & $2(8.7 \%)$ & \\
\hline Depression with psychotic symptoms & & $212.5 \%)$ & & \\
\hline Missing diagnosis & & $6(37.5 \%)$ & $1(4.3 \%)$ & \\
\hline Duration of untreated psychosis [months] & $11.3(16.6)$ & & $11.3(16.6)$ & \\
\hline Duration of untreated illness [months] & $52.5(59.1)$ & $47.9(37.7)$ & $55.8(71.6)$ & 0.665 \\
\hline Hippocampus right volume $\left[\mathrm{mm}^{3}\right]$ & $3162(235)$ & $3194(216)$ & $3140(249)$ & 0.470 \\
\hline Hippocampus left volume $\left[\mathrm{mm}^{3}\right]$ & $2841(256)$ & $2956(251)$ & $2761(232)$ & 0.020 \\
\hline Pituitary volume $\left[\mathrm{mm}^{3}\right]$ & $537(106)$ & $541(119)$ & $535(98.5)$ & 0.860 \\
\hline Grey matter volume $\left[\mathrm{cm}^{3}\right]$ & $681(55.8)$ & $680(57.5)$ & $681(55.9)$ & 0.983 \\
\hline Antipsychotic-naive & $25(64.1 \%)$ & $11(68.8 \%)$ & $14(60.9 \%)$ & 0.869 \\
\hline Antipsychotics currently & $13(33.3 \%)$ & $4(25.0 \%)$ & $9(39.1 \%)$ & 0.565 \\
\hline Chlorpromazine equivalent dose [mg] & $250(153)$ & $262(149)$ & $244(163)$ & 0.851 \\
\hline
\end{tabular}

FEP = First episode psychosis; ARMS-T = Patients with an at-risk mental state for psychosis and later transition to psychosis. Categorical variables are presented as absolute numbers and percentages in parenthesis and were compared with Chi-square or Fisher's Exact tests. Continuous variables are presented with means and standard deviations in parentheses and were compared with Welch's two sample t-tests.

${ }^{1}$ Diagnoses in ARMS-T after transition to psychosis 
Table 2: Hippocampus, pituitary, and grey matter volumes regressed on duration of untreated psychosis (DUP) and other covariates in first episode psychosis (FEP) patients

\begin{tabular}{lcccccc}
\hline & \multicolumn{3}{c}{ Hippocampus } & \multicolumn{2}{c}{ Pituitary } & \multicolumn{2}{c}{ Grey matter } \\
\cline { 2 - 7 } Term & Coef & $p$-value & Coef & $p$-value & Coef & $p$-value \\
\hline DUP $(\log )$ & 0.016 & 0.937 & 0.393 & 0.073 & -0.107 & 0.530 \\
DUP $(\log ) \times$ Hemisphere & 0.096 & 0.577 & & & & \\
Age & -0.277 & 0.224 & -0.056 & 0.805 & -0.488 & $0.012^{*}$ \\
Hemisphere & 0.262 & 0.128 & & & & \\
Sex & -0.229 & 0.728 & 0.002 & 0.997 & 1.424 & $0.002^{\star *}$ \\
Whole brain volume & 0.365 & 0.185 & 0.259 & 0.350 & & \\
Coef = regression coefficient; DUP $=$ duration of untreated psychosis. Dummy coding of binary \\
variables: Sex: men=-0.5, women=0.5; Hemisphere: left=-0.5, right=0.5. All independent and \\
dependent variables except binary variables were $z$-transformed before model fitting. \\
\hline
\end{tabular}


Table 3: Hippocampus, pituitary, and grey matter volumes regressed on duration of untreated illness (DUI) and other covariates in first episode psychosis (FEP) and prodromal (ARMS-T) patients combined

\begin{tabular}{|c|c|c|c|c|c|c|}
\hline \multirow[b]{2}{*}{ Term } & \multicolumn{2}{|c|}{ Hippocampus } & \multicolumn{2}{|c|}{ Pituitary } & \multicolumn{2}{|c|}{ Grey matter } \\
\hline & Coef & $p$-value & Coef & $p$-value & Coef & $p$-value \\
\hline DUI (log) & -0.073 & 0.689 & 0.118 & 0.499 & 0.039 & 0.813 \\
\hline DUI $(\log ) \times$ Group & 0.147 & 0.701 & 0.079 & 0.829 & -0.741 & $0.027^{*}$ \\
\hline DUI $(\log ) \times$ Group x Hemisphere & 0.184 & 0.460 & & & & \\
\hline DUI (log) x Hemisphere & -0.012 & 0.923 & & & & \\
\hline Age & -0.229 & 0.152 & 0.027 & 0.859 & -0.268 & 0.065 \\
\hline Group & -0.494 & 0.127 & -0.125 & 0.683 & -0.046 & 0.871 \\
\hline Group x Hemisphere & 0.560 & $0.016^{*}$ & & & & \\
\hline Hemisphere & -0.020 & 0.861 & & & & \\
\hline Sex & 0.028 & 0.941 & -1.058 & $0.007^{* *}$ & 0.772 & $0.019^{*}$ \\
\hline Whole brain volume & 0.170 & 0.356 & 0.244 & 0.171 & & \\
\hline
\end{tabular}

Coef $=$ regression coefficient; DUP $=$ duration of untreated psychosis. Dummy coding of binary variables: Sex: $m e n=-0.5$, women $=0.5$; Hemisphere: left=-0.5, right=0.5; Group: ARMS-T=-0.5, $\mathrm{FEP}=0.5$. All independent and dependent variables except binary variables were $z$-transformed before model fitting. 


\section{References}

Adriano, F., Caltagirone, C., Spalletta, G., 2012. Hippocampal volume reduction in first-episode and chronic schizophrenia: a review and meta-analysis. Neuroscientist 18 (2), 180-200.

Anderson, K.K., Rodrigues, M., Mann, K., Voineskos, A., Mulsant, B.H., George, T.P., McKenzie, K.J., 2015. Minimal evidence that untreated psychosis damages brain structures: a systematic review. Schizophr Res 162 (1-3), 222-233.

Andreasen, N.C., 1983. Scale for the assessment of negative symptoms. University of lowa, lowa City

Antonova, E., Sharma, T., Morris, R., Kumari, V., 2004. The relationship between brain structure and neurocognition in schizophrenia: a selective review. Schizophr Res 70 (2-3), 117-145.

Aston, J., Rechsteiner, E., Bull, N., Borgwardt, S., Gschwandtner, U., Riecher-Rössler, A., 2010. Hyperprolactinaemia in early psychosis-not only due to antipsychotics. Prog Neuropsychopharmacol Biol Psychiatry 34 (7), 1342-1344.

Bangalore, S.S., Goradia, D.D., Nutche, J., Diwadkar, V.A., Prasad, K.M., Keshavan, M.S., 2009. Untreated illness duration correlates with gray matter loss in first-episode psychoses. Neuroreport 20 (7), 729-734.

Borgwardt, S.J., McGuire, P.K., Aston, J., Berger, G., Dazzan, P., Gschwandtner, U., Pflüger, M., D'Souza, M., Radü, E.W., Riecher-Rössler, A., 2007. Structural brain abnormalities in individuals with an at-risk mental state who later develop psychosis. Br J Psychiatry Suppl 51, s69-75.

Borgwardt, S.J., McGuire, P.K., Aston, J., Gschwandtner, U., Pflueger, M.O., Stieglitz, R.D., Radue, E.W., Riecher-Rössler, A., 2008. Reductions in frontal, temporal and parietal volume associated with the onset of psychosis. Schizophr Res 106 (2-3), 108-114.

Borgwardt, S.J., Radue, E.W., Götz, K., Aston, J., Drewe, M., Gschwandtner, U., Haller, S., Pflueger, M., Stieglitz, R.D., McGuire, P.K., Riecher-Rössler, A., 2006. Radiological findings in individuals at high risk of psychosis. J Neurol Neurosurg Psychiatry 77 (2), 229-233.

Broussard, B., Kelley, M.E., Wan, C.R., Cristofaro, S.L., Crisafio, A., Haggard, P.J., Myers, N.L., Reed, T., Compton, M.T., 2013. Demographic, socio-environmental, and substance-related predictors of duration of untreated psychosis (DUP). Schizophrenia research 148 (1), 93-98.

Buehlmann, E., Berger, G.E., Aston, J., Gschwandtner, U., Pflueger, M.O., Borgwardt, S.J., Radue, E.W., Riecher-Rossler, A., 2010. Hippocampus abnormalities in at risk mental states for psychosis? A cross-sectional high resolution region of interest magnetic resonance imaging study. J Psychiatr Res 44 (7), 447-453.

Büschlen, J., Berger, G.E., Borgwardt, S.J., Aston, J., Gschwandtner, U., Pflueger, M.O., Kuster, P., Radü, E.W., Stieglitz, R.D., Riecher-Rössler, A., 2011. Pituitary volume increase during emerging psychosis. Schizophr Res 125 (1), 41-48.

Chua, S.E., Cheung, C., Cheung, V., Tsang, J.T., Chen, E.Y., Wong, J.C., Cheung, J.P., Yip, L., Tai, K.S., Suckling, J., McAlonan, G.M., 2007. Cerebral grey, white matter and csf in nevermedicated, first-episode schizophrenia. Schizophr Res 89 (1-3), 12-21.

Crespo-Facorro, B., Roiz-Santianez, R., Pelayo-Teran, J.M., Gonzalez-Blanch, C., Perez-Iglesias, R., Gutierrez, A., de Lucas, E.M., Tordesillas, D., Vazquez-Barquero, J.L., 2007a. Caudate nucleus volume and its clinical and cognitive correlations in first episode schizophrenia. Schizophr Res 91 (1-3), 87-96.

Crespo-Facorro, B., Roiz-Santianez, R., Pelayo-Teran, J.M., Rodriguez-Sanchez, J.M., PerezIglesias, R., Gonzalez-Blanch, C., Tordesillas-Gutierrez, D., Gonzalez-Mandly, A., Diez, C., Magnotta, V.A., Andreasen, N.C., Vazquez-Barquero, J.L., 2007b. Reduced thalamic volume in first-episode non-affective psychosis: correlations with clinical variables, symptomatology and cognitive functioning. Neuroimage 35 (4), 1613-1623.

Crumlish, N., Whitty, P., Clarke, M., Browne, S., Kamali, M., Gervin, M., McTigue, O., Kinsella, A., Waddington, J.L., Larkin, C., 2009. Beyond the critical period: Iongitudinal study of 8-year outcome in first-episode non-affective psychosis. Br J Psychiatry 194 (1), 18-24.

de Castro-Manglano, P., Mechelli, A., Soutullo, C., Landecho, I., Gimenez-Amaya, J.M., Ortuno, F., McGuire, P., 2011. Structural brain abnormalities in first-episode psychosis: differences between affective psychoses and schizophrenia and relationship to clinical outcome. Bipolar Disord 13 (5-6), 545-555.

de la Fuente-Sandoval, C., León-Ortiz, P., Favila, R., Stephano, S., Mamo, D., Ramírez-Bermúdez, J., Graff-Guerrero, A., 2011. Higher levels of glutamate in the associative-striatum of subjects with prodromal symptoms of schizophrenia and patients with first-episode psychosis. Neuropsychopharmacology 36 (9), 1781-1791. 
Dean, D.J., Orr, J.M., Bernard, J.A., Gupta, T., Pelletier-Baldelli, A., Carol, E.E., Mittal, V.A., 2016. Hippocampal Shape Abnormalities Predict Symptom Progression in Neuroleptic-Free Youth at Ultrahigh Risk for Psychosis. Schizophr Bull 42 (1), 161-169.

Fusar-Poli, P., Borgwardt, S., Bechdolf, A., Addington, J., Riecher-Rössler, A., Schultze-Lutter, F., Keshavan, M., Wood, S., Ruhrmann, S., Seidman, L.J., 2013. The psychosis high-risk state: a comprehensive state-of-the-art review. JAMA psychiatry 70 (1), 107-120.

Fusar-Poli, P., Radua, J., Frascarelli, M., Mechelli, A., Borgwardt, S., Fabio, F., Biondi, M., loannidis, J., David, S.P., 2013. Evidence of reporting biases in voxel-based morphometry (VBM) studies of psychiatric and neurological disorders. Human brain mapping.

Garcia-Rizo, C., Fernandez-Egea, E., Oliveira, C., Justicia, A., Parellada, E., Bernardo, M., Kirkpatrick, B., 2012. Prolactin concentrations in newly diagnosed, antipsychotic-naive patients with nonaffective psychosis. Schizophr Res 134 (1), 16-19.

Garner, B., Pariante, C.M., Wood, S.J., Velakoulis, D., Phillips, L., Soulsby, B., Brewer, W.J., Smith, D.J., Dazzan, P., Berger, G.E., Yung, A.R., van den Buuse, M., Murray, R., McGorry, P.D., Pantelis, C., 2005. Pituitary volume predicts future transition to psychosis in individuals at ultrahigh risk of developing psychosis. Biol Psychiatry 58 (5), 417-423.

Harris, M.G., Henry, L.P., Harrigan, S.M., Purcell, R., Schwartz, O.S., Farrelly, S.E., Prosser, A.L., Jackson, H.J., McGorry, P.D., 2005. The relationship between duration of untreated psychosis and outcome: an eight-year prospective study. Schizophrenia research 79 (1), 85-93.

Heckers, S., Konradi, C., 2002. Hippocampal neurons in schizophrenia. J Neural Transm 109 (5-6), 891-905.

Ho, B.C., Alicata, D., Mola, C., Andreasen, N.C., 2005. Hippocampus volume and treatment delays in first-episode schizophrenia. Am J Psychiatry 162 (8), 1527-1529.

Ho, B.C., Alicata, D., Ward, J., Moser, D.J., O'Leary, D.S., Arndt, S., Andreasen, N.C., 2003. Untreated initial psychosis: relation to cognitive deficits and brain morphology in first-episode schizophrenia. Am J Psychiatry 160 (1), 142-148.

Hoff, A.L., Sakuma, M., Razi, K., Heydebrand, G., Csernansky, J.G., DeLisi, L.E., 2000. Lack of association between duration of untreated illness and severity of cognitive and structural brain deficits at the first episode of schizophrenia. Am J Psychiatry 157 (11), 1824-1828.

Ittig, S., Studerus, E., Riecher-Rössler, A., 2016. A possible role for prolactin in emerging psychosis, $5^{\text {th }}$ Biennial SIRS Conference. npj Schizophrenia, Florence, p. 22.

Kappos, L., Antel, J., Comi, G., Montalban, X., O'Connor, P., Polman, C.H., Haas, T., Korn, A.A., Karlsson, G., Radue, E.W., 2006. Oral fingolimod (FTY720) for relapsing multiple sclerosis. New England Journal of Medicine 355 (11), 1124-1140.

Keshavan, M.S., Haas, G., Miewald, J., Montrose, D.M., Reddy, R., Schooler, N.R., Sweeney, J.A., 2003. Prolonged untreated illness duration from prodromal onset predicts outcome in first episode psychoses. Schizophrenia Bulletin 29 (4), 757-769.

Keshavan, M.S., Haas, G.L., Kahn, C.E., Aguilar, E., Dick, E.L., Schooler, N.R., Sweeney, J.A., Pettegrew, J.W., 1998. Superior temporal gyrus and the course of early schizophrenia: progressive, static, or reversible? J Psychiatr Res 32 (3-4), 161-167.

Koolschijn, P.C., van Haren, N.E., Cahn, W., Schnack, H.G., Janssen, J., Klumpers, F., Hulshoff Pol, H.E., Kahn, R.S., 2010. Hippocampal volume change in schizophrenia. J Clin Psychiatry 71 (6), 737-744.

Lappin, J.M., Morgan, K., Morgan, C., Hutchison, G., Chitnis, X., Suckling, J., Fearon, P., McGuire, P.K., Jones, P.B., Leff, J., Murray, R.M., Dazzan, P., 2006. Gray matter abnormalities associated with duration of untreated psychosis. Schizophr Res 83 (2-3), 145-153.

MacMaster, F.P., Keshavan, M., Mirza, Y., Carrey, N., Upadhyaya, A.R., El-Sheikh, R., Buhagiar, C.J., Taormina, S.P., Boyd, C., Lynch, M., Rose, M., Ivey, J., Moore, G.J., Rosenberg, D.R., 2007. Development and sexual dimorphism of the pituitary gland. Life Sci 80 (10), 940-944.

Malla, A.K., Bodnar, M., Joober, R., Lepage, M., 2011. Duration of untreated psychosis is associated with orbital-frontal grey matter volume reductions in first episode psychosis. Schizophr Res 125 (1), 13-20.

Marshall, M., Lewis, S., Lockwood, A., Drake, R., Jones, P., Croudace, T., 2005. Association between duration of untreated psychosis and outcome in cohorts of first-episode patients: a systematic review. Arch Gen Psychiatry 62 (9), 975-983.

Mondelli, V., Pariante, C.M., Navari, S., Aas, M., D'Albenzio, A., Di Forti, M., Handley, R., Hepgul, N., Marques, T.R., Taylor, H., Papadopoulos, A.S., Aitchison, K.J., Murray, R.M., Dazzan, P., 2010. Higher cortisol levels are associated with smaller left hippocampal volume in first-episode psychosis. Schizophr Res 119 (1-3), 75-78. 
Nordholm, D., Krogh, J., Mondelli, V., Dazzan, P., Pariante, C., Nordentoft, M., 2013. Pituitary gland volume in patients with schizophrenia, subjects at ultra high-risk of developing psychosis and healthy controls: a systematic review and meta-analysis. Psychoneuroendocrinology 38 (11), 2394-2404.

Norman, R.M., Malla, A.K., 2001. Duration of untreated psychosis: a critical examination of the concept and its importance. Psychol Med 31 (3), 381-400.

Pantelis, C., Velakoulis, D., McGorry, P.D., Wood, S.J., Suckling, J., Phillips, L.J., Yung, A.R., Bullmore, E.T., Brewer, W., Soulsby, B., Desmond, P., McGuire, P.K., 2003. Neuroanatomical abnormalities before and after onset of psychosis: a cross-sectional and longitudinal MRI comparison. Lancet 361 (9354), 281-288.

Pariante, C.M., Dazzan, P., Danese, A., Morgan, K.D., Brudaglio, F., Morgan, C., Fearon, P., Orr, K., Hutchinson, G., Pantelis, C., Velakoulis, D., Jones, P.B., Leff, J., Murray, R.M., 2005. Increased pituitary volume in antipsychotic-free and antipsychotic-treated patients of the AEsop first-onset psychosis study. Neuropsychopharmacology 30 (10), 1923-1931.

Pariante, C.M., Vassilopoulou, K., Velakoulis, D., Phillips, L., Soulsby, B., Wood, S.J., Brewer, W., Smith, D.J., Dazzan, P., Yung, A.R., Zervas, I.M., Christodoulou, G.N., Murray, R., McGorry, P.D., Pantelis, C., 2004. Pituitary volume in psychosis. Br J Psychiatry 185, 5-10.

Penttila, M., Jaaskelainen, E., Haapea, M., Tanskanen, P., Veijola, J., Ridler, K., Murray, G.K., Barnes, A., Jones, P.B., Isohanni, M., Koponen, H., Miettunen, J., 2010. Association between duration of untreated psychosis and brain morphology in schizophrenia within the Northern Finland 1966 Birth Cohort. Schizophr Res 123 (2-3), 145-152.

Perkins, D.O., Gu, H., Boteva, K., Lieberman, J.A., 2005. Relationship between duration of untreated psychosis and outcome in first-episode schizophrenia: a critical review and meta-analysis. Am J Psychiatry 162 (10), 1785-1804.

Phillips, L.J., Velakoulis, D., Pantelis, C., Wood, S., Yuen, H.P., Yung, A.R., Desmond, P., Brewer, W., McGorry, P.D., 2002. Non-reduction in hippocampal volume is associated with higher risk of psychosis. Schizophr Res 58 (2-3), 145-158.

Polari, A., Lavoie, S., Sarrasin, P., Pellanda, V., Cotton, S., Conus, P., 2011. Duration of untreated psychosis: a proposition regarding treatment definition. Early Interv Psychiatry 5 (4), 301-308.

R Development Core Team, 2012. R: A Language and Environment for Statistical Computing. R Foundation for Statistical Computing, Vienna, Austria.

Rapp, C., Studerus, E., Bugra, H., Aston, J., Tamagni, C., Walter, A., Pflueger, M., Borgwardt, S., Riecher-Rössler, A., 2013. Duration of untreated psychosis and cognitive functioning. Schizophr Res 145 (1-3), 43-49.

Riecher-Rössler, A., Ackermann, T., Uttinger, M., Ittig, S., Koranyi, S., Rapp, C., Bugra, H., Studerus, E., 2015. Das Basler Interview für Psychosen (BIP): Struktur, Reliabilität und Validität. Fortschr Neurol Psychiatr 83 (2), 99-108.

Riecher-Rössler, A., Aston, J., Ventura, J., Merlo, M., Borgwardt, S., Gschwandtner, U., Stieglitz, R.D., 2008. [The Basel Screening Instrument for Psychosis (BSIP): development, structure, reliability and validity]. Fortschr Neurol Psychiatr 76 (4), 207-216.

Riecher-Rössler, A., Gschwandtner, U., Aston, J., Borgwardt, S., Drewe, M., Fuhr, P., Pflüger, M., Radü, W., Schindler, C., Stieglitz, R.D., 2007. The Basel early-detection-of-psychosis (FePsy)study - design and preliminary results. Acta Psychiatr Scand 115 (2), 114-125.

Riecher-Rössler, A., Rybakowski, J.K., Pflueger, M.O., Beyrau, R., Kahn, R.S., Malik, P., Fleischhacker, W.W., 2013. Hyperprolactinemia in antipsychotic-naive patients with first-episode psychosis. Psychol Med, 1-12.

Rund, B.R., 2014. Does active psychosis cause neurobiological pathology? A critical review of the neurotoxicity hypothesis. Psychol Med 44 (8), 1577-1590.

Small, S.A., Schobel, S.A., Buxton, R.B., Witter, M.P., Barnes, C.A., 2011. A pathophysiological framework of hippocampal dysfunction in ageing and disease. Nature Reviews Neuroscience 12 (10), 585-601.

Smith, S.M., Rao, A., De Stefano, N., Jenkinson, M., Schott, J.M., Matthews, P.M., Fox, N.C., 2007. Longitudinal and cross-sectional analysis of atrophy in Alzheimer's disease: cross-validation of BSI, SIENA and SIENAX. Neuroimage 36 (4), 1200-1206.

Smith, S.M., Zhang, Y., Jenkinson, M., Chen, J., Matthews, P., Federico, A., De Stefano, N., 2002. Accurate, robust, and automated longitudinal and cross-sectional brain change analysis. Neuroimage 17 (1), 479-489.

Takahashi, T., Suzuki, M., Tanino, R., Zhou, S.Y., Hagino, H., Niu, L., Kawasaki, Y., Seto, H., Kurachi, M., 2007. Volume reduction of the left planum temporale gray matter associated with long 
duration of untreated psychosis in schizophrenia: a preliminary report. Psychiatry Res 154 (3), 209-219.

Velakoulis, D., Wood, S.J., Smith, D.J., Soulsby, B., Brewer, W., Leeton, L., Desmond, P., Suckling, J., Bullmore, E.T., McGuire, P.K., 2002. Increased duration of illness is associated with reduced volume in right medial temporal/anterior cingulate grey matter in patients with chronic schizophrenia. Schizophrenia research 57 (1), 43-49.

Velakoulis, D., Wood, S.J., Wong, M.T., McGorry, P.D., Yung, A., Phillips, L., Smith, D., Brewer, W., Proffitt, T., Desmond, P., Pantelis, C., 2006. Hippocampal and amygdala volumes according to psychosis stage and diagnosis: a magnetic resonance imaging study of chronic schizophrenia, first-episode psychosis, and ultra-high-risk individuals. Arch Gen Psychiatry 63 (2), 139-149.

Ventura, J., Lukoff, D., Nuechterlein, K., Liberman, R., Green, M., Shaner, A., 1993. Manual of the expanded brief psychiatric rating scale. Int J Methods Psychiatr Res(3), 227-243.

Vita, A., De Peri, L., Deste, G., Barlati, S., Sacchetti, E., 2015. The effect of antipsychotic treatment on cortical gray matter changes in schizophrenia: does the class matter? A meta-analysis and meta-regression of longitudinal magnetic resonance imaging studies. Biol Psychiatry 78 (6), 403-412.

Walker, E., Mittal, V., Tessner, K., 2008. Stress and the hypothalamic pituitary adrenal axis in the developmental course of schizophrenia. Annu Rev Clin Psychol 4, 189-216.

Walker, E.F., Trotman, H.D., Pearce, B.D., Addington, J., Cadenhead, K.S., Cornblatt, B.A., Heinssen, R., Mathalon, D.H., Perkins, D.O., Seidman, L.J., Tsuang, M.T., Cannon, T.D., McGlashan, T.H., Woods, S.W., 2013. Cortisol levels and risk for psychosis: initial findings from the North American Prodrome Longitudinal Study. Biol Psychiatry.

Walter, A., Studerus, E., Smieskova, R., Kuster, P., Aston, J., Lang, U.E., Radue, E.-W., RiecherRössler, A., Borgwardt, S., 2012a. Hippocampal volume in subjects at high risk of psychosis: A longitudinal MRI study. Schizophrenia research 142 (1), 217-222.

Walter, A., Studerus, E., Smieskova, R., Kuster, P., Aston, J., Lang, U.E., Radue, E.W., RiecherRossler, A., Borgwardt, S., 2012b. Hippocampal volume in subjects at high risk of psychosis: a longitudinal MRI study. Schizophr Res 142 (1-3), 217-222.

Walter, A., Studerus, E., Smieskova, R., Tamagni, C., Rapp, C., Borgwardt, S.J., Riecher-Rossler, A., 2014. Pituitary gland volume in at-risk mental state for psychosis: a longitudinal MRI analysis. CNS Spectr, 1-8.

Witthaus, H., Kaufmann, C., Bohner, G., Ozgurdal, S., Gudlowski, Y., Gallinat, J., Ruhrmann, S., Brune, M., Heinz, A., Klingebiel, R., Juckel, G., 2009. Gray matter abnormalities in subjects at ultra-high risk for schizophrenia and first-episode schizophrenic patients compared to healthy controls. Psychiatry Res 173 (3), 163-169.

Wood, S.J., Kennedy, D., Phillips, L.J., Seal, M.L., Yücel, M., Nelson, B., Yung, A.R., Jackson, G., McGorry, P.D., Velakoulis, D., Pantelis, C., 2010. Hippocampal pathology in individuals at ultrahigh risk for psychosis: a multi-modal magnetic resonance study. Neuroimage 52 (1), 62-68.

Wyatt, R.J., Henter, I., 2001. Rationale for the study of early intervention. Schizophr Res 51 (1), 69-76.

Yung, A.R., Phillips, L.J., McGorry, P.D., McFarlane, C.A., Francey, S., Harrigan, S., Patton, G.C., Jackson, H.J., 1998. Prediction of psychosis. A step towards indicated prevention of schizophrenia. Br J Psychiatry Suppl 172 (33), 14-20. 